\title{
Evaluation of How Studying a Clinical Case Influences Medical Students' Capabilities for Performing a Lumbar Puncture Four Weeks Later
}

\author{
Hanne Storm*
}

Skills Training Centre, Medical Faculty, University of Oslo, Norway

\begin{abstract}
Objective: The objective of this study is to evaluate medical students' perceptions of acceptability of a simulation-based lumbar puncture (LP) course and its effect on standardized LP performance four weeks later. Tests were also conducted to find out whether skills were improved by including a clinical case to establish the relevance of the learning material in the LP course.

Methods: Medical students in their pediatric term $(n=45)$ were invited to participate and were randomly divided into three groups. The simulation group was offered only the LP course, while the simulation and clinical case group was offered a clinical case leading to performing LP on an infant before attending the actual LP course. The groups were tested four weeks after the LP courses together with a control group that had attended neither the LP course nor the clinical case. The testing was conducted by awarding points, up to a maximum of 26, for the different correct actions performed during the LP procedure.

Results: The medical students in the skill group $(\mathrm{n}=11)$ performed similarly to the students in the skill and clinical case group (n=9), $14.2(+/-4.4)$ and $13.9(+/-4.3)$ respectively, and better than the control group, $(\mathrm{n}=10) 5.6(+/-4.8)(\mathrm{p}<0.01)$.

Conclusions: When tested, the medical students who had completed the LP course performed better than the control group that had not been offered this course during their pediatric term. Hence, introducing a clinical case in the LP course did not improve LP skills.
\end{abstract}

Keywords: Clinical case; Lumbar puncture course; Simulation-based training; Questionnaire.

\section{INTRODUCTION}

Simulation is well established within healthcare training and practice. An extensive body of literature verifies its use for learning clinical procedures, both simple and advanced [1]. Compared to other ways of teaching, clinical skills would seem easier to master because students tend to remember $90 \%$ of what they do but only $10 \%$ of what they read [2]. Procedures range from venipuncture and tying surgical knots to highly complex surgical operations, while the simulations themselves range from simple physical models to sophisticated virtual reality computer systems [3]. Simulation technology increases procedural skills by providing the opportunity for deliberate practice in a safe environment [4]. There has been even more focus on this topic since the Objective Structured Clinical Examination (OSCE) was established at many medical universities worldwide. As technology advances, and as the climate of clinical education puts more emphasis on simulation as a safe substitute for practicing on "real" patients, the range of available simulations will inevitably increase. It is therefore appropriate to examine the characteristics of a successful simulation in terms of learning and clinical outcome.

*Address correspondence to this author at the Skills Training Centre, Medical Faculty, University of Oslo, Norway; Tel: + 47 90788976;

+ 47 23074398; Fax: + 47 22546678; E-mail: hanne.storm@medisin.uio.no
The teaching as well as the assessment of clinical skills are important in medical training [5]. Assessment is one important step in the learning and teaching process. There are several testing models, e.g. written papers with different question formulas, computer-aided assessment and oral exams, as well as practical exams with actual or standardized (simulated) patients. A recent development has been made to increase the testing of medical students in many aspects regarding their clinical skills. Most medical schools have well established assessment formulas and routines for teaching and testing medical students which were implemented for good reasons in the past. They should, however, certainly be reconsidered when new needs arise and when new opportunities or concepts become available.

Medical literature shows that performing more repetitions of procedures leads to greater confidence in performing those procedures $[1,6,7]$. The locations of the peripheral venous line [8], the central venous lines [9], as well as the intubation [10] have been studied which revealed that increased exposure to a specific procedure improves the knowledge and skills required for that particular procedure. In one study, first-year residents reported that $29 \%$ of interns had not yet performed a lumbar puncture (LP) during medical school, and only 9\% had performed more than five LPs [11]. One study of acting interns reported that the majority of medical students felt comfortable performing most proce- 
dures again except for LP [12]. A literature search did not, however, find that this skill had been tested in medical students together with a clinical case. The skills training center at the Faculty of Medicine at the University of Oslo is based on the model from the University of Maastricht in the Netherlands [13]. Here medical student instructors are taught by professors who are specialized in the different topics and who are mainly responsible for teaching the different courses. Both the level of competence and knowledge and the manuals for the different courses are quality assured by these professors. The question of the need to repeat the courses is always asked: how often and with which time frame should the repetition be performed? The question is also raised as to whether more clinical information should be added to the simulation-based courses to establish the relevance of the learning material and subsequently improve the learning process of the skills.

The objective of this study is to evaluate medical students' perceptions of the acceptability of a simulation-based LP course and its effect on standardized LP performance four weeks later during their pediatric term (one year after their neurological term). Tests were also conducted to find out whether skills were improved by including a clinical case in the course.

\section{METHODS}

\section{Design}

\section{Questionnaire}

After the medical students had completed their courses in the neurological term one year prior to the pediatric term, a questionnaire developed by the Faculty of Medicine at the University of Oslo was used to evaluate whether the medical students found the LP simulation-based course acceptable for learning LP skills. The questionnaire is simple and informative, and it explores objectively whether the course has the satisfactory level required by the medical students (Table $\mathbf{1}$ ).

\section{Trial}

To conduct the trial, the pediatric term was chosen because by then all the medical students had completed the neurology term and should thus have learned how to perform an LP. It was expected that the medical students were motivated to perform their newly acquired LP skills during the pediatric term when LP is also a topic from a clinical point of view. Medical students in their pediatric term $(n=45)$ were asked if they wanted to participate in the trial. They were informed how the test was organized and about the three different groups. The medical students who participated were voluntarily and randomly divided into three groups. The simulation group was offered only the LP course, while the simulation and clinical case group was offered a clinical case leading to performing LP on an infant (see Table 2) before performing the LP course itself. A pediatrician discussed this clinical case with individual medical students in the simulation and case group for about 15 minutes. Four weeks after the LP courses the groups were tested in simulation together with a control group that had attended neither the LP course nor the clinical case. The testing was conducted by awarding points, up to a maximum of 26, for the different correct actions performed during the LP procedure (see Table 3). The set-up of the test is shown in Fig. (1). Lumbar Puncture Simulator II, Limbs \& Things Ltd., Sussex Street, Bristol, UK, was used in the test (see Fig. 1).

The medical student instructors conducted both the LP simulation-based courses as well as evaluating the participating medical students when they were tested with the LP test. The medical student instructors were taught by the professor of neurology who was in charge of the lectures on the performance of the LP. Once the testing had been completed, the medical student instructors were asked whether the LP course and LP testing they had been conducting had been easy or difficult to perform.

Table 1. Evaluation Questionnaire from the Student Section, Medical Faculty, UIO, Used to Examine if the Medical Students Found the Level of the Simulation-based Lumbar Puncture Course Satisfactory During the Neurological term.
Too little/slow
Satisfactory
Too much/fast
1. Amount of learning
2. Tempo:
3. Amount of detail :
Not engaging/relevant
Extremely engaging/relevant
12
34
5
4. Relevant:
5. Performance:
6. Total impression:

Anything more to add? 
Table 2. A Pediatrician Discussed this Clinical Case with Medical Students Individually in the Simulation and Case Group for about 15 Minutes

You are the doctor on call in the pediatric department. One night you are called upon because a patient is brought to the emergency department by his parents. You are told that a boy, Christian, 11 months old, has been feverish and it was noted that he had become pale and silent and had also developed strange movements just five minutes ago. As the family lives next door, they took him directly to the pediatric emergency department.

1. You will make a quick evaluation of Christian (max. 1 min.) to see whether he is really critically ill and needs emergency treatment. How would you proceed? Keywords only.

2. Categorize the listed alternatives by your immediate evaluation of the patient into one of the two categories:

\section{Check for rash} Should be done May wait/irrelevant

Examine for standing skin folds

Examine capillary refill

Respiratory distress?

Check for neck stiffness

Palpate lymphatic glands

Examine the fontanel

Conduct Kerning's test

Heart percussion

Communicate with the patient

Check for dry mucous membranes

Strange movements?

Check heart rate

3. At your immediate evaluation you find:

- Christian is irritable and is not easily awakened, but responds to manipulation.

- No respiratory distress

- Heart rate $170 / \mathrm{min}$.

- No neck stiffness

- He is pale, with cold extremities, capillary refill > 2 sec

- No exanthema

- Generally slightly reduced tone, symmetric movements

4. What is Christian's differential diagnosis?

5. You will gather more information about the patient prior to further examination and treatment. What are your prioritized questions?

6. You get to know:

- Christian has been well prior to this event, and has been on the established vaccination programmer.

- He has been ill for 18 hours.

- His illness started with a high temperature.

- He has vomited the last six hours.

- He has been irritable and drowsy the past three hours.

- Jerky movements of the left arm for two minutes prior to arrival at the hospital.

7. Among your findings are:

- $\quad$ Rectal temperature $38,9{ }^{\circ} \mathrm{C}$

- $\quad$ BP 90/50

- Normal fontanel

- Heart/lungs/abdomen/oropharynx clear

- $\quad$ Slight hypotonia, symmetric movements

8. Fifteen minutes have passed since Christian's arrival at the hospital. You evaluate his condition as unchanged. Are there any possible diagnoses you consider less likely given the time aspect and the information you have gathered? Write these down.

9. You will continue your examination and treatment of Christian. Evaluate the following statements for right (R) and wrong (W):

R W

$\square \quad \square$ Tachycardia is an early sign of septicemia in infants

Monitoring of blood pressure is important in this patient

Hypothermia may be a sign of septicemia

Early complete neurological examination is of high priority in this case

An intravenous line should wait till after completion of the clinical examination

A normal fontanel greatly reduces the probability of meningitis in this patient

Examination for neck-stiffness requires a different technique in infants than in adults

Kerning's test is a sensitive test for meningitis in this patient

Tachypnea is a sensitive parameter for septicemia and meningitis in infants

\section{Statistics}

The results of the questionnaire regarding the LP simulation-based course are presented with mean (+/-SD). There are about 90 medical students in each term, and $50 \%$ of these were carrying out their pediatric practice weeks when the LP trial was conducted, whereas the other $50 \%$ were undergoing their gynecological practice period. Based on Barsuk’s 2012 study performed on residents both with and without experience of the simulation-based LP skill course, the skills acquired after the LP course increased with nearly no overlap between the residents who had performed the course compared to the residents who had not performed the course [14]. The aim of this study was to include about ten medical students randomly in each of the three groups: the skill and case group, the skill group and the control group. The result 
Table 3. Testing Protocol of Medical Students During their Course on Pediatrics based on the Simulation-based Lumbar Puncture (LP) Course, Max 26 Points

\begin{tabular}{|c|c|c|c|}
\hline & $\begin{array}{l}\text { Procedure Checklist Skill Item for Lum- } \\
\text { bar Puncture (LP) }\end{array}$ & Correct Results & Evaluation Points \\
\hline 1. & $\begin{array}{l}\text { The students shall pick out the tools they } \\
\text { need for the examination and prepare for LP }\end{array}$ & $\begin{array}{l}\text { Cleaning kit, chlorhexidine, sterile gloves, } \\
\text { needle, spinal fluid manometer, plaster, com- } \\
\text { press } \\
\text { Testing tubes; cells, spinal glucose, viral serol- } \\
\text { ogy, bacteriology and special examination } \\
\text { Also equipment not necessary for LP was } \\
\text { available, see testing table, Figure } 1 \text {. }\end{array}$ & $\begin{array}{l}3 \text { points (- } 1 / 2 \text { point for each thing forgotten, - } \\
1 / 2 \text { point for each second thing which is unnec- } \\
\text { essary). } \\
1 / 2 \text { point for each correct tube market with its } \\
\text { content. }\end{array}$ \\
\hline 2. & $\begin{array}{l}\text { Demonstrate knowledge of correct anatomic } \\
\text { location for the LP procedure }\end{array}$ & $\begin{array}{l}\text { Palpation of cristae iliaca, both sides and show a } \\
\text { fictive line between the upper cristae iliaca } \\
\text { superior, level L3-L4. } \\
\text { Palpation the deepest space between the two } \\
\text { processi spinosi, } \\
\text { Mark or show the stick spot with the nail or a } \\
\text { pen in middle line, L3-L4, L4-L5, and L5-S1 are } \\
\text { acceptable. }\end{array}$ & $\begin{array}{l}1 \text { point } \\
1 \text { point } \\
1 \text { point }\end{array}$ \\
\hline 3. & Washing the back & $\begin{array}{l}\text { Tell the patient you will wash his back. } \\
\text { Put on sterile gloves. } \\
\text { Wash sterile in circles from the location of the } \\
\text { injection spot }\end{array}$ & $\begin{array}{l}1 \text { point } \\
1 \text { point } \\
1 \text { point }\end{array}$ \\
\hline 4. & Installing the needle & $\begin{array}{l}\text { Take the needle in the hand, localization of the } \\
\text { stick spot with opposite hand and establish the } \\
\text { needle in the location of the injection spot. } \\
\text { Tell the patient that you will give an injection. } \\
\text { Quick injection through the skin } \\
\text { Correct angle of the needle toward umbilicus } \\
\text { with the stylet. Slowly advance the needle with } \\
\text { periodic checking CSF (removal of stylet) until } \\
\text { space entered. } \\
\text { Place the stylet into the needle when preparing } \\
\text { the manometer in order to avoid losing CS. }\end{array}$ & $\begin{array}{l}1 \text { point } \\
1 \text { point } \\
1 \text { point } \\
1 \text { point } \\
1 \text { point }\end{array}$ \\
\hline 5. & Manometer & $\begin{array}{l}\text { Connect the manometer to the needle. } \\
\text { Keep the manometer vertically from the injec- } \\
\text { tion spot on a correct level, and measure open- } \\
\text { ing pressure. }\end{array}$ & $\begin{array}{l}1 \text { point } \\
1 \text { point }\end{array}$ \\
\hline 6. & Collect CSF & $\begin{array}{l}\text { Collect CSF to the different tubes and reset the } \\
\text { stylet. }\end{array}$ & 1 point \\
\hline 7. & Remove the needle and place dressing. & $\begin{array}{l}\text { The needle is removed and sterile compress with } \\
\text { tape is placed above the injection spot. }\end{array}$ & 1 point \\
\hline 8. & Use of time & $\begin{array}{l}\text { Less than } 7.5 \mathrm{~min} \text { OK } \\
\text { More than } 7.5 \mathrm{~min} \\
\text { More than } 10 \mathrm{~min}\end{array}$ & $\begin{array}{l}-3 \text { points } \\
-6 \text { points }\end{array}$ \\
\hline 9. & $\begin{array}{l}\text { The general expression including maintain } \\
\text { of sterile technique }\end{array}$ & Careful and accurate procedure/performance & $1-5$ points \\
\hline
\end{tabular}

numbers of the testing are given with mean (SD) and (range). Non-parametric tests (Mann-Whitney U test for two samples) to compare the groups were performed between the skill and skill-case group, the skill and the control group, and between the skill-case group as well as the control group. The statistical significant value was $\mathrm{p}<0.05$. 


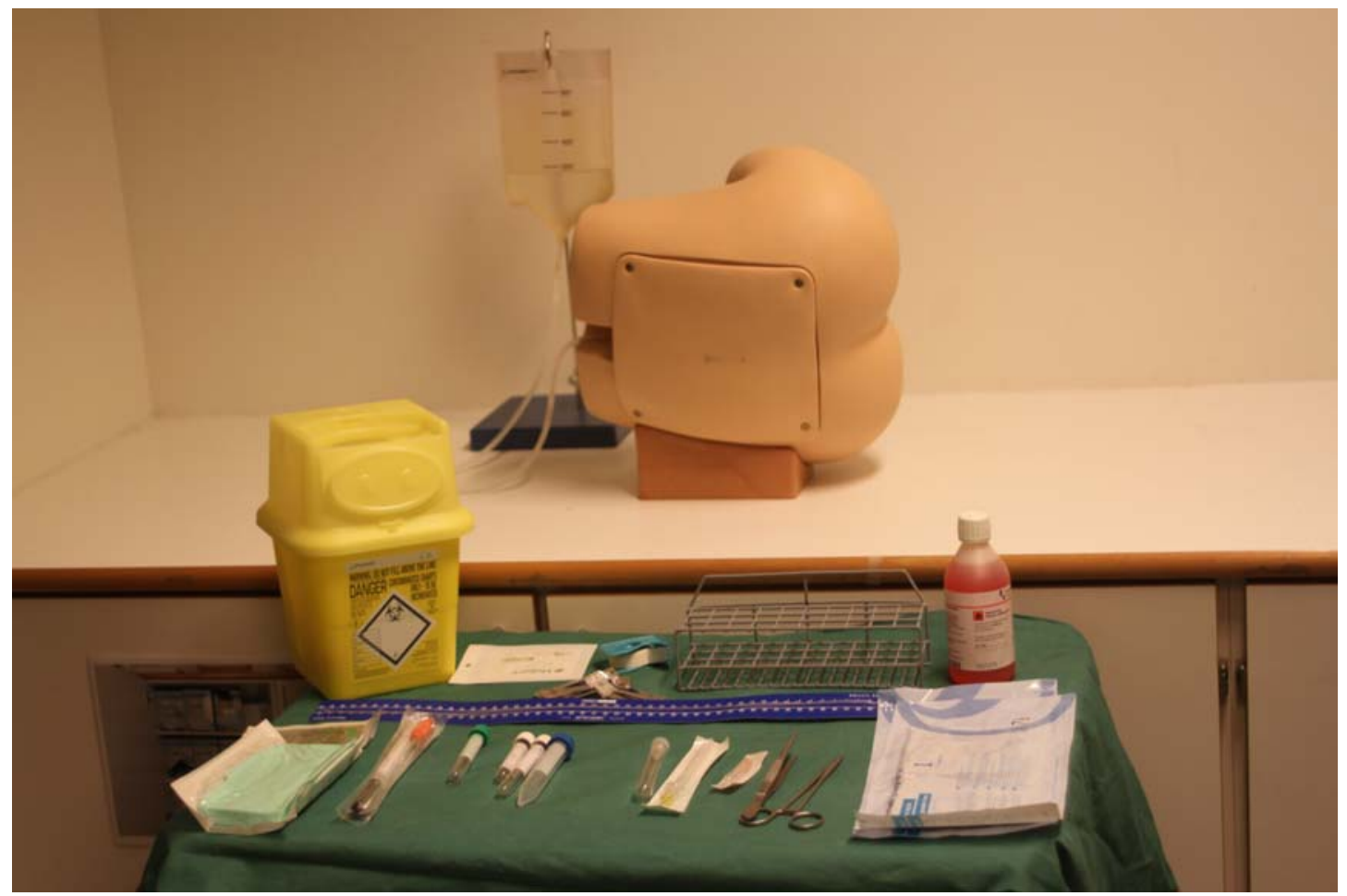

Fig. (1). Photograph of the trial set up prior to the simulation-based lumbar puncture testing.

\section{RESULTS}

When using the questionnaire developed for evaluating the lectures at the University of Oslo, the LP simulationbased course was evaluated by medical students who had completed the neurological term as appropriate regarding the amount of learning material, tempo and degree of detail (see Table 4). Table $\mathbf{4}$ also shows that the medical students found the courses relevant, and considered the performance and total value to be satisfactory. Thirty students participated in this voluntary study. The medical students in the skill group $(n=11)$ performed on a similar level when compared to the students in the skill and clinical case group $(\mathrm{n}=9)$, with a mean of $14.2(+/-4.4)(7.1-21)$ and $13.9(+/-4.3)(9.8-21)$ respectively, and better than the control group $(\mathrm{n}=10)$ with a mean of $5.6(+/-48)(-1-17),(\mathrm{p}<0.01)$. There were four student instructors who gave the LP courses and who passed judgment when the medical students were tested for the LP procedure. All these medical student instructors were of the view that both the simulation-based LP course and the LP testing were easy to conduct.

\section{DISCUSSION}

The purpose of this study, conducted during the pediatric term, was to evaluate the medical students' perceptions of acceptability of a simulation-based lumbar puncture (LP) course and its effect on standardized LP performance four weeks later. Tests were also conducted to find out whether skills were improved by including a clinical case to establish the relevance of the learning material in the LP course. The LP simulation-based course was evaluated as appropriate by medical students who had completed the neurological term regarding the amount of learning material, tempo and degree of details. The medical students also found the courses relevant and considered performance and total value to be satisfactory. The medical students in the skill group performed on a similar level when compared to the students in the skill and clinical case group, and better than the control group. The results of the testing of the effect of the skills both including and not including a clinical case revealed that statistically speaking the skill and clinical case group and the skill group performed significantly better than the control group. Interestingly, this study was not able to find that a clinical case to establish the relevance of the learning material in the course improved the LP skills. One reason for this may possibly be the low number of medical students in the groups. Another reason might be that these medical students already clearly saw the relevance. The medical students' perceptions of the LP simulation-based course should be similar among the groups since the students had the same neurological background. A bias related to this aspect is possible although

Table 4. Results of Evaluation of the Simulation-based Lumbar Puncture Course from the Validation form Performed by the Medical Students During the Neurology Term, mean +/-SD

\begin{tabular}{|l|l|}
\hline Amount of learning material & $3.1+/-0.5$ \\
\hline \hline Tempo & $3.0+/-0.3$ \\
\hline Amount of details & $2,9+/-03$ \\
\hline Relevant & $4.4+/-0.5$ \\
\hline Performance & $4.3+/-0.5$ \\
\hline Total evaluation & $4.3+/-0.4$ \\
\hline
\end{tabular}


improbable. The number of participants in this study was based on the number of residents in the Barsuk, et al. 2012 study where the results after the LP simulation-based course showed an improvement without overlap compared to the performance of the residents who had not completed the course [14]. In our study, however, all the medical students had passed their exams in neurology. This examination had taken place one year previously during the term in which LP was one of the teaching goals. Nonetheless, those medical students who did not complete the LP course during the pediatric term performed poorly. This indicates that there is a need for repetitive skill courses. In addition, the medical students who completed their courses four weeks prior to the testing did not have particularly high test scores. Possible reasons may be that high test scores were too difficult to obtain, see Table 3 , that the examiner did not give sufficient extra marks ( 5 available, see Table 3 ) for the general impression, or that during the four weeks between the course and the testing the medical students forgot the skills from the course - a course that was not compulsory during the pediatric term. In another study, the testing of the LP skills of residents was performed immediately after the simulation course, and the improvement in skills then increased dramatically [14]. In Barsuk's 2012 study the residents were also tested in a clinical situation that required LP skills, and were therefore particularly motivated to learn these skills. When testing internal medicine residents' LP skills, a minimum pass score level was developed. Prior to the LP skills course, hardly any of the residents obtained the minimum pass score. After the LP skills course, however, all the residents obtained the pass score [14]. It would possibly be interesting to introduce a minimum pass score for medical students that should be obtained in the skills training center before allowing medical students to perform LP on patients. Interestingly, patients are more willing to allow medical students to perform procedures such as venipuncture, LP or central lines on them after they have undergone simulation training [15]. Published literature on the subject tells us that learning LP vicariously by observing procedures performed by peers should not be recommended. This method of learning leads to uneven skill acquisition and trainee discomfort [16]. The medical student instructors, who both taught the medical students on the LP simulation-based course and evaluated these students when they were tested, reported that the method was easy to perform.

Improperly performed medical procedures carry a high risk of adverse medico-legal and personal health consequences and may cause patient harm and even death. Techniques and established methods for evaluating the performance of medical procedures are therefore needed. Modeling and simulation have gained acceptance, and evaluation "in vivo" has been suggested as the best method [17]. Others suggest that technical skills might be moved from the clinical setting into simulation laboratories. Interestingly, when evaluating twelve technical skills of 20 surgical residents both "in vivo" and at simulation models, the two methods performed similarly in most respects $[18,19]$. Simulation has been used to evaluate possible gaps in the skill of medical students and residents during the management of acutely ill patients [20]. In the study conducted by Young et al. in 2007, medical students and residents were assessed in their management of high-risk scenarios and Young et al. tried to find a steady increase in performance for each level of lecture-based and problem-based training. Worth noting is that when the medical students and residents were assessed, they performed equally poorly in comparison with the expertattending comparison group [21]. This performance deficit indicated that there might be a deficiency in the current model of the lecture-based and problem-based learning model of teaching. For this reason there may be potential dangers within the current medical system regarding residents deciding to perform critical actions. As a teaching tool, simulation-based teaching has proved to be superior to the traditional problem-based learning model. When fourth-year medical students were randomized to receive a problembased learning or simulation-based teaching training intervention for the management of acute dyspnea, the results showed that the group receiving the simulation intervention performed significantly better with a greater improvement in scores from baseline than the problem-based learning group [22]. Furthermore, 208 medical students demonstrated significant improvement in clinical skills and knowledge when they were trained on a cardiology patient simulator during a fourth-year cardiology apprenticeship in comparison with standard bedside teaching $[23,24]$. Similar findings have been shown in medical house staff during simulation-based teaching $[25,26]$. Simulation technology gives us the opportunity to develop valid, reliable and workable methods to assess clinical skills. The simulation courses cost relatively little to implement, especially when performed by medical student instructors on low salaries.

To conclude, this study demonstrates that a simulationbased course boosts LP skills in medical students. Including a clinical case in the course did not improve the performance of LP skills in this study. Based on these results, we believe that a procedural standard in LP skills at the skills training center should be set and documented for all medical students prior to them performing LP in actual clinical care.

\section{CONFLICT OF INTEREST}

The authors confirm that this article content has no conflicts of interest.

\section{ACKNOWLEDGEMENTS}

I would like to thank pediatrician Erik Hankø who conducted the clinical case part of the course and led the clinical case group. I further like to thanks the instructors at the skills simulation centre who helped to run the courses and the testing.

\section{REFERENCES}

[1] Okuda Y, Bryson EO, DeMaria S, et al. The utility of simulation in medical education: what is the evidence? Mt Sinai J Med 2009; 76: 330-43.

[2] Croley WC, Rothenberg DM. Education of trainees in the intensive care unit. Crit Care Med 2007; 35(suppl): S117-S-21.

[3] Kneebone R. Simulation in surgical training: educational issues and practical implications. Med Educ 2003; 37: 267-77.

[4] Issenberg SB, Gordon DL, Safford RE, Hart IR. Simulation and new learning technologies. Med Teach 2001; 23(1): 16-23.

[5] Issenberg SB, McGaghie WC, Hart IR, et al. Simulation technology for health professionals skills training an assessment. JAMA 1999; 282: 861-6. 
[6] Hicks CM, Gonzales R, Morton MT, Gibbsons RV, Wigton RS, Anderson RJ. Procedural experience and comfort level in internal medicine trainees. J Gen Intern Med 2000; 15: 716-22.

[7] Connick RM, Connick P, Klotsas AE, Tsagkaraki PA, GkraniaKlotsas E. Procedural confidence in hospital-based practitioners: implications for the training and practice of doctors at all grades. BMC Med Educ 2009; 9: 2.

[8] Gaies MG, Moris SA, Hafler JP, et al. Reforming procedural skills training for pediatric residents: a randomized, interventional trial. Pediatrics 2009; 124(2): 610-9.

[9] Barsuk JH, McGafhie WC, Cohen ER, Balachandran JS, Wayne DB. Use of simulation-based mastery learning to improve the quality of central venous catheter placement in a medical intensive care unit. J Hosp Med 2009; 4: 397-403.

[10] Hall RE, Plant JR, Bands CJ, Wall AR, Kang J, Hall CA. Human patient simulation is effective for teaching paramedic students endotracheal intubation. Acad Emerg Med 2005; 12: 850-5.

[11] Promes SB, Chudgar SM, Grichowski CO, et al. Gaps in procedural experience and competency in medical school graduates. Acad Emerg Med. 2009; 16: S58-S62.

[12] Cberly L, Goldenhar LM. Ready or not, here they come: acting interns' experience and perceived competency performing basic medical procedures. J Gen Intern Med 2007; 22: 491-94.

[13] Visser K, Prince KJ, Scherpbier AJ, Van der Vleuten CP, Verwijnen GM. Students can be full partners in designing their education. A quality assessment of skills training. Acad Med 1997; 72(12): 1034-5.

[14] Barsuk J, Cohen ER, Caprio T, McGaghie WC, Simuni T, Wayne DB. Simulation-based education with mastery learning improves residents' lumbar puncture skills. Neurology 2012; 79: 132-7.

[15] Graber MA, Wyatt C, Kasparek L, Xu Y. Does simulator training for medical students change patient opinions and attitudes toward medical student procedures in the emergency department? Acad Emerg Med 2005; 12: 635-9.
[16] Lynagh M, Burton R, Sanson-Fisher R. A systematic review of medical skills laboratory training: where to from here? Med Educ 2007; 41: 879-87.

[17] Huang GC, Smith CC, Gordon CE, et al. Beyond the comfort zone: residents assess their comfort performing in-patient medical procedures. Am J Med 2006; 119: 71.

[18] Watts J, Feldman WB. Assessment of Technical Skills in Assessing Competence. New York: Springer 1985; pp. 259-74.

[19] Reznick RK. Teaching and testing technical skills. Am J Surg 1993: 259-74.

[20] Martin J, Reghr G, Reznick R, et al. Objective structured assessment of technical skill (OSATS) for surgical residents. Br J Surg 1997; 84(2): 273-8.

[21] Young JS, Dubose JE, Hedrick TL, Conaway MR, Nolley B. The use of "war games" to evaluate performance of students and residents in basic clinical scenarios: a disturbing analysis. J Trauma 2007; 63: 556-64.

[22] Steadman RH, Coates WC, Huang YM, et al. Simulation-based training is superior to problem-based learning for the acquisition of critical assessment and management skills. Crit Care Med 2006; 34: 151-7.

[23] Okuda Y, Quinones J. The use of simulation in the education of emergency care providers of cardiac emergencies. Int J Emerg Med 2008; 1: 73-7.

[24] Ewy GA, Felner JM, Juul D, Mayer JW, Sajid AW, Waugh RA. Test of a cardiology patient simulator with students in fourth-year electives. J Med Educ 1987; 62: 738-43.

[25] Issenberg SB, Gordon MS, Greber AA. Bedside cardiology skills training for the osteopathic internist using simulation technology. J Am Osteopath Assoc 2003; 103: 603-7.

[26] Issenberg SB, McGaghie WC, Gordon DL, et al. Effectiveness of a cardiology review course for internal residents using simulation technology and deliberate practice. Teach Learn Med 2002; 14: 223-8.

(c) Hanne Storm; Licensee Bentham Open.

This is an open access article licensed under the terms of the Creative Commons Attribution Non-Commercial License (http://creativecommons.org/licenses/by-nc/3.0/) which permits unrestricted, non-commercial use, distribution and reproduction in any medium, provided the work is properly cited. 